\title{
POSTFIRE AVIAN ECOLOGY IN YELLOWSTONE NATIONAL PARK
}

\author{
Robert J. Jonas \& Allan R. Pfister \\ Washington State University
}

\section{Objectives}

One objective of establishing Yellowstone National Park was to minimize human influence on the biotic communities. However, from the time of establishment (1872) through 1972, the policy was to suppress forest fires. Since natural fires play an important role in many environments, their importance to the Yellowstone ecosystem is being assessed. Little knowledge exists on avian succession immediately following a forest fire and several years postfire.

Considering that fires naturally occur in forest habitats every 100 to 200 years (Cole 1975), the Divide fire burn on the western side of the South Arm of Yellowstone Lake and the Trail Creek fire burn southeast of the Southeast Arm of Yellowstone Lake provided an opportunity to supplement the knowledge of Yellowstone's fire ecology. Therefore the objective of this project was to initiate the determination of avian ecology in these postfire areas of Yellowstone Park. Reports resulting from this study will be valuable for future management and in following postfire trends in the avian community.

\section{Procedures}

Considerable time was spent in April and May 1978 (prior to formal funding of this project) in literature search, planning, conferences, obtaining maps and materials, etc. Subsequent to formal funding (September through November 1978) data collation was commenced.

The field phase of the research was initiated June 12, 1978 and terminated September 1, 1978. Study plots were established in the 1600 acre Divide fire burn and the 580 acre Trail Creek fire burn within clean burn areas ( 580 and 280 acres respectively). Twenty-two and two-tenth acre ( 9 hectare) study plots permitting censusing the avian populations in those areas were established on June 13 (Divide) and July 1 and 2 (Trail Creek). In the Trail Creek area a 22.2 acre plot, located southeast of the burn plot was also established in an unburned section of forest as control. To encompass an environment similar to the Divide fire burn, an unburned plot of 11.1 acres was established June 14 and 15 .

Areas on which the spot-map technique were to be utilized, with the exception of the Divide unburned plot, were 300 meters on a side delineated with double flagging on the exterior, with single flagging on the interior. The Divide unburned plot was 300 meters by 150 meters, and was delineated in the same manner. All plots were gridded in 25 meter intervals and marked as an 
$X-Y$ coordinate system to facilitate observation recording. Wooden stakes were placed on all even-numbered $X-Y$ coordinates $(00 / 00,20 / 00,20 / 20$, etc.).

Line transects, 600 meters in length, were established along the Divide and Trail Creek edges created by the fires, on June 26 and July 7 respectively. Two 300 meter lines within the burned and unburned plots on both areas were utilized to comprise the 600 meters needed for line transects. All line transects were marked at 25 meter intervals with single flagging, with the exception of the endpoints which were marked with double flagging.

An attempt to determine avian density was by the use of the spot-map technique (Williams 1936) and line transect censuses. Censuses were conducted in early morning and early evening using both audio and visual aids to determine avian species present. Mist nets were erected in both areas in an attempt to determine if any species were present, but not recorded by the techniques described above.

Field observations were recorded on printed sheets utilizing a computer symbol check-list for species, activity, location, number, etc. All species encountered were also placed in their respective feeding categories in relation to foraging level and food type according to the method used by Salt (1953).

Approximately 111 hours were spent censusing the avian communities from June 13 to August 31 ; 56 hours on the Divide fire area and 55 on the Trail Creek area. Spot mapping the Divide area required 14 hours for the burn and 12 hours for the control, while the line transect required 30 hours; 10 each for the burn, control, and edge. A minimum of 21 hours was spent casually observing avian species present in the study and adjacent areas. In instances where nests were located, the diameter at breast height (DBH), tree height, and the number of young (if possible) were recorded. These data will be used for calculations of standing crop biomass and consuming biomass (Salt 1957) and of species diversity (Tramer 1969).

Using canopy coverage, vegetation was studied by establishing two 285 meter lines within each plot and sampling at 15 mețer intervals along the line. The sample plot was a $4 \mathrm{~m}^{2}$ circle. Vegetation data for the line transects (edges) was collected along the lines previously established. The categories for which coverage data were obtained were: grasses, shrubs, forbs, logs, bare ground, and trees. Diameter at breast height (DBH) was also recorded and divided into height class categories for five $25 \mathrm{~m}^{2}$ plots in an effort to determine critical nesting criteria in a burned area. Approximately 45 hours were spent collecting vegetation data in each of the two areas. These data will be used to compare the vegetation ecology of the edges, unburned controls, and burned areas.

Results and Conclusions:

General differences in the species composition of the burned and unburned areas were noted through the course of the censusing. Eight species were encountered only on the burns, while six species were encountered only in the controls. Several species not found in the burns were found in both the control and along the edges. Thirteen species were recorded as using both burned and unburned forests, though relative densities are presently not 
available. These general, preliminary findings seem to indicate that natural fires, through their alteration of the existing forest habitat, enhance ecological diversity.

\section{Acknowledgments}

We express our appreciation for the invaluable assistance provided by the personnel of Yellowstone National Park, especially Dr. Don Despain. Among those whom we would like to express special thanks are Don Chase, Janey McDowe 1l, Roger Rudolph, John Scott, Bob Romanowitz, and George Monroe. This study was funded by the University of Wyoming - National Park Service Research Center with ancillary support from Washington State University.

\section{Literature Cited}

Cole, G. F. 1975. Nature and man in Yellowstone National Park. Information Paper No. 28. YNP,NPS.

Salt, G. W. 1953. An ecological analysis of three California avifaunas. Condor 55(5): 258-273.

Salt, G. W. 1957. An analysis of avifaunas in the Teton Mountains and Jackson Hole, Wyoming. Condor 59(6): 373-393.

Tramer, E. J. 1969. Bird species diversity; components of Shannon's formula. Ecology 50: 927-929.

Williams, A. B. 1936. The composition and dynamics of a beech-maple climax community. Ecol. Monogr. 6: 317-408. 